\title{
Evolution of Circulating C-Terminal Propeptide of Type I Procollagen in Patients with Chronic Renal Failure Pre and Post Renal Transplantation
}

\author{
Maria R. Bonnin'. Maria T. Gonzalez², José M. Griñón', José M. Cruzado², José M. Martínez ${ }^{2}$ and \\ Miguel A. Navarro \\ 1 Hormone Unit, Biochemistry Service, Ciudad Sanitaria y Universitaria, de Bellvitge, Feixa Llarga s.n., \\ L'Hospitalet de Llobregat, Barcelona, Spain \\ 2 Nephrology Service, Ciudad Sanitaria y Universitaria de Bellvitge, Barcelona, Spain
}

Summary: The carboxyterminal propeptide of type I procollagen is a biochemical marker of type I collagen synthesis. We evaluated circulating carboxyterminal propeptide of type I procollagen levels in patients with terminal renal failure before and after kidney transplantation. Serum carboxyterminal propeptide of type I procollagen, osteocalcin, total alkaline phosphatase, intact parathyrin, creatinine, calcium and phosphate levels were determined in 20 patients, before and 15, 30, 90 and 180 days after surgery. Serum creatinine and intact parathyrin concentrations showed a significant decrease after kidney transplantation. Immunosuppressive treatment consisted of low dose prednisone, cyclosporin and antilymphoblast globulin.

In our group, only 5 patients (25\%) showed serum carboxyterminal propeptide of type I procollagen levels higher than normal before kidney transplantation. At 15 and 30 days, carboxyterminal propeptide of type I procollagen concentrations showed a decrease, while at 90 and 180 days there was a significant increase above the normal range $(p=0.006$; ANOVA). Serum osteocalcin and total alkaline phosphatase levels increased significantly at the same time. We found a significant correlation between carboxyterminal propeptide of type I procollagen and osteocalcin at 15 and 30 days after kidney transplantation. We conclude that the significant increase in carboxyterminal propeptide of type I procollagen levels after kidney transplantation reflect an increase in bone turnover. The low doses of steroids employed do not seem to have a significant inhibitory effect on collagen synthesis.

\section{Introduction}

The carboxyterminal propeptide of type I procollagen is the main protein secreted by the osteoblast, and it arises from the cleavage of a large precursor of type I collagen by a specific proteolytic enzyme (1). It is found in the free form in blood where its concentration is considered to reflect the rate of type I collagen synthesis, and it is therefore considered to be a marker of bone formation (2).

In rats, it has been shown that carboxyterminal propeptide of type I procollagen is bound to and internalized into endothelial cells of the liver by receptor mediated endocytosis (3). As it is primarily degraded by the liver we may suppose that its excretion will not be affected by glomerular retention. The theoretical advantage of measuring carboxyterminal propeptide of type I procollagen rather than other markers of bone formation like osteocalcin or total alkaline phosphatase, is the fact that carboxyterminal propeptide of type I procollagen is the major synthetic product of osteoblasts (4). However, there are other sites of type I collagen synthesis, such as skin, that contribute to the circulating levels of procollagen peptides (5). Parathyrin and calcitriol seem to affect collagen synthesis but the results are controversial
(6-8). In patients with chronic renal failure with high parathyrin levels and a diminished calcitriol production (9), serum carboxyterminal propeptide of type I procollagen levels may be affected.

It is known that glucocorticoids inhibit the synthesis of interstitial procollagen, so that their administration will decrease the carboxyterminal propeptide of type I procollagen concentration in blood (10).

The aim of this study was to follow carboxyterminal propeptide of type I procollagen secretion in a group of transplant patients with good renal function throughout the entire study period, comparing these data with sequential serum osteocalcin and total alkaline phosphatase levels, and to evaluate the influence of posttransplant corticosteroid therapy.

\section{Materials and Methods}

Subjects

We studied a group of 20 patients (10 males and 10 females, mean age 42.3 years, range $18-66$ years) with chronic renal failure and affected with varying degrees of secondary hyperparathyroidism. who received a cadaveric kidney transplantation. None of the patients had undergone parathyroidectomy, and all of those with pre- 
vious hyperparathyroidism received oral supplements of calcitrio prior to transplantation. The post transplant immunosuppressive therapy consisted of prednisone $(0.5 \mathrm{mg} / \mathrm{kg} \times \mathrm{d}$ progressivcly decreased to $0.1 \mathrm{mg} / \mathrm{kg} \times \mathrm{d}$ ), as well as cyclosporin $A$ (dose adjusted by monitoring with monoclonal antibody) and antilymphoblast globulin on alternate days up to 5 or 6 doses (11).

Blood samples were obtained sequentially prior to transplantation and $15,30,90$ and 180 days afterwards. We measured serum creatinine, calcium. phosphate, total alkaline phosphatase, intact parathyrin. osteocalcin and carboxyterminal propeptide of type I procollagen. Liver function was assessed in all patients by determination of $\gamma$-glutamyltransferase and alanine aminotransferase. $\mathrm{Pa}$ tients with impaired liver function were excluded from the study. The procedures followed were in accordance with the ethical standards of our institution's responsible committee.

\section{Analytical methods}

Serum concentrations of creatinine, calcium, phosphate and total alkaline phosphatase were routinely determined in our laboratory on a BM/Hitachi 717 analyser using Boehringer Mannheim kits.

Serum intact parathyrin was measured by immunoradiometric assay (Incstar Corp., Stillwater MN), using the reference interval of $1.1-4.6 \mathrm{pmol} / \mathrm{l}$ as determined in our laboratory (12). Inter-assay coefficient of variation $(\mathrm{CV})$ was $7.1 \%$ and $7.6 \%$ at 4.1 and 41.1 $\mathrm{pmol} / \mathrm{l}$ respectively.

Serum osteocalcin was determined by immunoradiometric assay (ELSA-OSTEO, CIS Bio-International, Gif-sur-Yvette, France) by means of two monoclonal antibodies against human osteocalcin. The reference interval, as established in our laboratory, was 19.8 $\pm 5.7(\bar{x} \pm \mathrm{s}) \mu \mathrm{g} / \mathrm{l}$ in men and $18.3 \pm 7.5 \mu \mathrm{g} / \mathrm{l}$ in women. No significant differences were found between sexes (13). The interassay $C V$ was $8.1 \%$ at $26.1 \mu \mathrm{g} / \mathrm{l}$.

Serum carboxyterminal propeptide of type I procollagen was assayed by a radioimmunoassay (Orion Diagnostica, Findland) based on human carboxyterminal propeptide of type I procollagen. Reference intervals were $50-170 \mu \mathrm{g} / 1$ and $38-202 \mu \mathrm{g} / \mathrm{l}$ for men and women respectively (Orion Diagnostica). The intraassay $\mathrm{CV}$ was $10.8 \%$ at $20.5 \mu \mathrm{g} / 1$.

\section{Statistical analysis}

Between and within subject differences were checked by the analysis of variance (ANOVA) for repeated measurements. The values showed a normal (Gaussian) distribution. Subgroup differences measured by the Scheffe test were neglected if the overall test was not significant. Correlation coefficients were obtained from the non-parametric Spearman rank test. The level of significance was defined in all tests as $\mathrm{p}<0.05$.

\section{Results}

After kidney transplantation, serum creatinine concentrations showed a marked decrease of about $75 \%$ with respect to basal values ( $p=0.0004$; ANOVA); in the most patients it was below $200 \mu \mathrm{mol} / \mathrm{l}$ at day 180 . Prior to kidney transplantation serum phosphate was significantly increased ( $p=0.0014$; ANOVA); these values decreased to normal levels after surgery. Serum calcium remained in the normal range throughout the study period. Seven patients had basal intact parathyrin in the normal range, probably due to calcitriol treatment, but mean overall values were higher than the normal range ( $20.5 \mathrm{pmol} / \mathrm{l}$ versus a reference value of $4.6 \mathrm{pmol} / \mathrm{l})$. After surgery, a progressive significant decrease in intact parathyrin levels was observed $(p=0.0001$; ANOVA), although in some patients they did not attain normal values even at day 180 .

Serum total alkaline phosphatase levels remained in the normal range before kidney transplantation and at 15 and 30 days after surgery; the values rose gradually at 90 and 180 days $(p<0.01)$.

Serum osteocalcin concentrations were increased to about eight times the normal values under basal conditions, showed a marked decrease during the first two weeks after surgery, then increasẹd significantly up to 180 days $(\mathrm{p}=0.002$; ANOVA $)$.

Prior to kidney transplantation only 5 patients had elevated serum carboxyterminal propeptide of type I procollagen levels (25\%), 4 of them with normal intact parathyrin levels. At 15 and 30 days after surgery carboxyterminal propeptide of type I procollagen concentrations showed decrease and a significant increase at 90 and 180 days $(p=0.006$; ANOVA). Table 1 shows mean absolute values of the three bone markers studied through the study period.

No significant correlations were found between carboxyterminal propeptide of type I procollagen/parathyrin, carboxyterminal propeptide of type I procollagen/osteocalcin and carboxyterminal propeptide of type I procollagen/ total alkaline phosphatase prior to kidney transplantation. In the follow-up we found a significant correlation only between carboxyterminal propeptide of type I procollagen and osteocalcin at 15 and 30 days $(r=0.48, p=0.05$ and $r=0.45, p=0.05$ respectively), although all three markers increased at the same time (fig. 1).

\section{Discussion}

Since carboxyterminal propeptide of type I procollagen is formed in a $1: 1$ stoichiometric ratio to type I collagen molecules, its serum levels are recognized markers of osteoblastic activity (2). In cross sectional studies on healthy adults, circulating carboxyterminal propeptide of type I procollagen concentrations have been found to

Tab. 1 Serum carboxyterminal propeptide of type I procollagen, osteocalcin and total alkaline phosphatase levels before and after kidney transplantation.

\begin{tabular}{llll}
\hline & $\begin{array}{l}\text { Carboxyterminal } \\
\text { propeptide } \\
\text { of type I } \\
\text { procollagen } \\
(\mu \mathrm{g} / \mathrm{l})\end{array}$ & Osteocalcin & $\begin{array}{l}\text { Total } \\
\text { alkaline } \\
\text { phosphatase }\end{array}$ \\
\hline Basal & $154.6 \pm 94.5$ & $231 \pm 286$ & $1.4 \pm 1.1$ \\
15 days & $133.4 \pm 59.8$ & $37 \pm 42$ & $1.32 \pm 0.79$ \\
30 days & $124.6 \pm 43.5$ & $32 \pm 30.5$ & $1.47 \pm 0.66$ \\
90 days & $205.0 \pm 89$ & $50 \pm 34.4$ & $2.01 \pm 1.23$ \\
180 days & $245.0 \pm 100$ & $75 \pm 42.8$ & $2.36 \pm 1.46$ \\
Normal range & $38.0-202$ & $3-33$ & $0.6-1.6$ \\
\hline
\end{tabular}

Numbers show means $\pm S D$ 
correlate with cancellous bone formation rate (14). A similar correlation has been found in osteoporosis (15) and renal osteodystrophy (16).

In a metabolic steady state, there is generally a good correlation between serum carboxyterminal propeptide of type I procollagen levels and other biochemical markers of bone formation, e. g. total alkaline phosphatase or osteocalcin. However each of these reflects different metabolic pathways of the osteoblast, and each assay has certain limitations (2). Total alkaline phosphatase is said to be a less sensitive marker of osteoblastic activity because it is also produced in other tissues (17). Bone alkaline phosphatase, which is the isoenzyme of skeletal origin, may improve the specificity and sensitivity. It is known that osteocalcin may also be released from bone matrix during bone resorption (18). Serum carboxyterminal propeptide of type I procollagen concentrations may measure bone matrix biosynthesis and reflect bone formation more directly, although other sites can contribute to circulating levels. The exact distribution of type I collagen between bones and soft tissues is not known, but the great majority is believed to be in bones (5).

Patients with long-standing renal failure are affected with varying degrees of secondary hyperparathyroidism. Calcitriol treatment reduces parathyrin levels and prevents hypertrophy of the parathyroid glands.
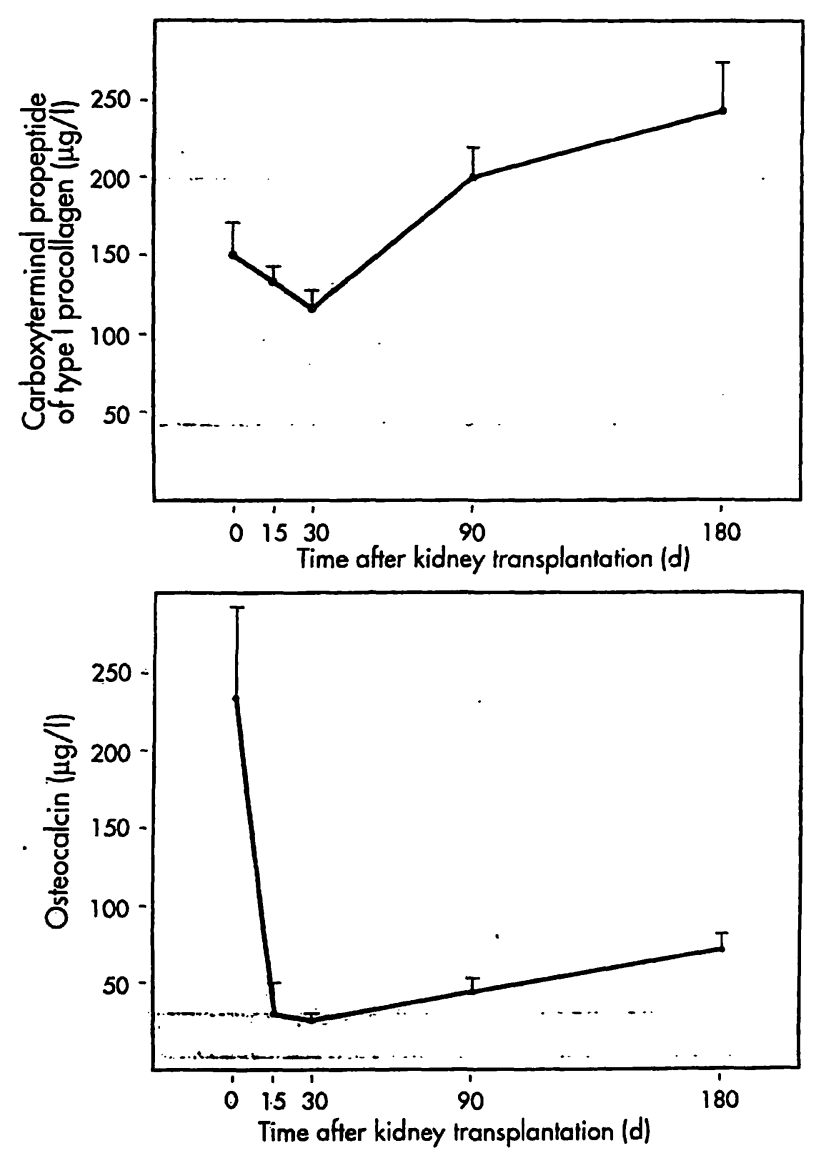

Fig. 1 Mean serum carboxyterminal propeptide of type I procollagen, intact parathyrin, osteocalcin and total alkaline phosphatase
Coen et al. found a significant decrease in serum carboxyterminal propeptide of type I procollagen levels in predialysis patients receiving calcitriol (16). These authors also found a significant correlation between dynamic histomorphometric quantities and carboxyterminal propeptide of type I procollagen serum levels in their patients.

It is known that after a successful renal transplantation serum parathyrin levels decrease and bone lesions tend to normalize, however the normalization of circulating parathyrin is not instantaneous, and variable periods are required from one patient to another to achieve normal levels, depending on previous glandular hypertrophy (19). The immunosuppressive drugs employed after kidney transplantation may influence the recovery of bone lesions.

In our group prior to transplantation all patients were receiving calcitriol supplementation. After renal transplantation the patients studied recovered good renal function but some patients had serum parathyrin concentrations above the normal range, even at 180 days.

Prior to surgery, mean serum carboxyterminal propeptide of type I procollagen levels were in the normal range, possibly due to the inhibitory effect of high intact parathyrin levels or induction by calcitriol treatment. At 15 and 30 days after kidney transplantation, carboxyterminal propeptide of type I procollagen levels were also
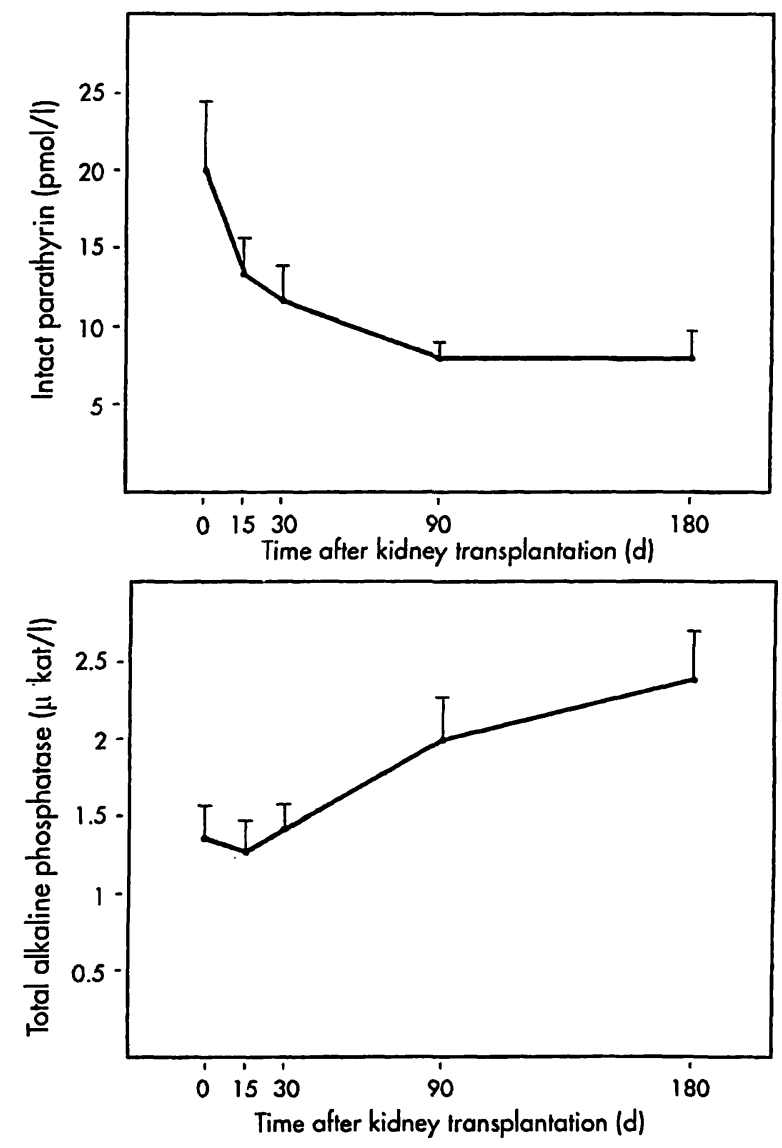

levels before and 15,30,90 and 180 days after kidney transplantation. Shadowed areas represent references ranges. 
in the normal range but lower than previously: the reference interval is relatively broad, so that even changes occurring within the reference interval may be important. The higher dose of corticosteroids employed during this period may be responsible for these changes. The significant increases in carboxyterminal propeptide of type I procollagen levels observed at 90 and 180 days may reflect an increase in osteoblastic activity that is not affected by the lower dose of corticosteroids used at this time.

There is no correlation between carboxyterminal propeptide of type I procollagen and parathyrin levels throughout the study period, in accordance with other authors (16); this fact suggests that other factors like calcitriol may be the main regulator of carboxyterminal propeptide of type I procollagen concentration.

Prior to transplantation we found no correlation between carboxyterminal propeptide of type I procolla-

\section{References}

1. Burgeson RE. New collagens, new concepts [review). Annu Rev Cell Biol 1988; 4:551-77.

2. Charles P, Hasling C, Risteli L, Risteli J, Mosekillde L, Ericsen EF. Assessment of bone formation by biochemical markers in metabolic bone disease: separation between osteoblastic activity at the cell and tissue level. Calcif Tissue Int 1992; $51: 406-11$.

3. Smedsrod B, Melkko J, Risteli L, Risteli J. Circulating C-terminal propeptide of type I procollagen is cleared mainly via mannose receptor in liver endothelial cells. Biochem J 1990; 271:345-50.

4. Azria $M$. The value of biomarkers in detecting alterations in bone metabolism [review]. Calcif Tissue Int 1989; 45:7-11.

5. Fessler JH, Fessler LI. Biosynthesis of procollagen. Annu Rev Biochem 1978; 47:129.

6. Partridge NC, Dickson CA, Kopp K, Teitelbaum SL, Crouch EC, Kahn AJ. Parathyroid hormone inhibits collagen synthesis at both ribonucleic acid and protein levels in rat osteogenic sarcoma cells. Mol Endocrinol 1989; 3:232-9.

7. Simon LS, Slovit DM, Neer RM, Krane SM. Changes in serum levels of type I and III procollagen extension peptides during infusion of human parathyroid hormone fragment [1-34]. J Bone Miner Res 1988; 3:241-6.

8. Gram J, Bollerslev J, Nielsen HK, Junker P. Increased serum concentrations of type I procollagen C-terminal propeptide and osteocalcin during a short course of calcitriol administration to adult male volunteers. Acta Endocrinol [Copenh] 1991; 125:609-13.

9. Coburn J. Renal osteodystrophy. Kidney International 1980; 17:677-93.

10. Oikarinen A, Autio P, Vuori J, Vaananen K, Risteli L, Kiistala U, Risteli J. Systemic glucocorticoid treatment decreases serum concentrations of carboxyterminal propeptide of type I procollagen and aminoterminal propeptide of type III procollagen. Br J Dermatol 1992; 126:172-8

11. Griño JM, Alsina J, Sabater R, Castelao AM, Gil-Vernet S, Andres $\mathrm{E}$, et al. Antilymphoblast globulin, cyclosporine and steroids in cadaveric renal normal transplantation. Transplantation 1990; 49:1114-7.

12. Bonnin MR, Gonzalez MT, Arranz B, Rosel P, Navarro MA. Intact parathyrin in patients after kidney transplantation [technical brief]. Clin Chem 1988; 34:2378.

13. Bonnin MR, Gonzalez MT, Moliner R, Cortes JD, Mateo L, gen levels and the other markers of bone formation studied, in accordance with previous reports (10), probably due to different functional osteoblastic states. After kidney transplantation the only significant correlation was that between carboxyterminal propeptide of type I procollagen and osteocalcin at 15 and 30 days, but the fact that the three markers increased at the same time signifies that the three bone formation markers behave similarly in all the patients. Small doses of corticosteroids do not seem to decrease circulating levels of the bone markers studied, in contrast with other studies $(10,20,21)$.

We conclude that the significant increase in carboxyterminal propeptide of type I procollagen levels at 90 and 180 days, above the reference interval, after kidney transplantation may reflect an increase in osteoblastic activity in these patients. The low doses of steroids employed in our treatment schedule do not seem to have a significant inhibitory effect on collagen synthesis.

Navarro MA. Assessment of human osteocalcin by an immunoradiometric assay [abstract]. Calcif Tissue Int 1994; 54:446.

14. Parfitt AM, Simon LS, Villanueva AR, Krane SM. Procollagen type I carboxyterminal extension peptide in serum as a marker of collagen biosynthesis in bone. Correlation with iliac bone formation rates and comparison with total alkaline phosphatase. J Bone Miner Res 1987; 2:427-36.

15. Eriksen EF, Charle P, Melsen F, Mosekilde L, Risteli L, Risteli J. Serum markers or type I collagen formation and degradation in metabolic bone disease: correlation to bone histomorphometry. J Bone Miner Res 1993; 8:127-32.

16. Coen G, Mazzaferro S, Ballanti P, Bonucci E, Bondatti F, Manni M, et al. Procollagen type I C-terminal extension peptide in predialysis chronic renal failure. Am J Nephrol 1992; 12:246-51

17. Duda RJ, O'Brien JF, Katzmann JA, Peterson JM, Mann KG, Riggs BL. Concurrent assays of circulating bone gla-protein and bone alkaline phosphatase: effects of sex, age and metabolic bone disease. J Clin Endocrinol Metab 1988; 66:951-7.

18. Kraenzlin ME, Taylor AK, Baylink DJ. Biochemical markers for bone formation and bone resorption. In: Lindh E, Thorell $\mathrm{JI}$, editors. Clinical impact of bone and connective tissue markers. San Diego, CA: Harcourt Brace Jovanovich, 1989:289303.

19. Alsina J, Gonzalez MT, Bonnin MR, Ricart Y, Castelao AM, Gonzalez C, Griño JM. Long term evolution of renal osteodystrophy after renal transplantation. Transpl Proceed 1989; 21:2151-8.

20. Reid IR, Chapman GE, Fraser TRC, Davies AD, Surus AS, Meyer J, et al. Low serum osteocalcin levels in glucocorticoidtreated asthmatics. J Clin Endocrinol Metab 1986; 62:379-83.

21. Lukert BP, Higgings JC, Stoskopf MM. Serum osteocalcin is increased in patients with hyperthyroidism and decreased in patients receiving glucocorticoids. J Clin Endocrinol Metab 1986; 62:1056-8.

\section{Received April 24/August 19, 1996}

Corresponding author: Dr. María R. Bonnin, $\mathrm{PhD}$, Hormone Unit. Biochemistry Service, Ciudad Sanitaria y Universitaria de Bellvitge, Feixa Llarga s. n., E-08907 L'Hospitalet de Llobregat, Barcelona, Spain 